\title{
STRATEGIES OF LEARNING ABSTRACT ALGEBRA
}

\author{
Ruma Manandhar Ph.D ${ }^{* 1}$ (iD), Lekhnath Sharma Ph.D 2 \\ ${ }^{*}$ Assistant Professor, Nepal Open University, Nepal \\ 2 Professor, Nepal Open University, Nepal \\ DOI: https://doi.org/10.29121/granthaalayah.v9.i1.2021.2697
}

Article Type: Research Article

Article Citation: Ruma Manandhar Ph.D, and Lekhnath Sharma PhD. (2021). STRATEGIES OF LEARNING ABSTRACT ALGEBRA. International Journal of Research -

GRANTHAALAYAH, 9(1), 1-6.

https://doi.org/10.29121/granthaa

layah.v9.i1.2021.2697

Received Date: 05 December 2020

Accepted Date: 20 January 2021

Keywords:

Strategies

Abstract

Algebra

\begin{abstract}
This article is based on the study, which tries to unpack strategies of learning abstract algebra from learners' perspective. Ethnography was used to collect the required information. The study found the strategies of learning abstract algebra are: to use idiosyncratic figure, analogical reasoning, particular concrete examples, and particular relation. This study can lead teachers of abstract algebra to a new awareness of their teaching strategies and their practices.
\end{abstract}

\section{INTRODUCTION}

"Mathematics is a product of the human mind and the possibilities of human rational thinking" (Maasz \& Schloeglmann, 2006, p.2). Devlin defined "modern Mathematics is about abstract pattern, abstract structure, and abstract relationships" (2000, p.136). Similarly, abstract algebra belongs to modern mathematics because it requires thinking with a high level of abstraction. Abstract algebra explores the possible relationship among abstractions. Many researchers report on students" and teachers" difficulties with learning and teaching abstract algebra that prevent them from fulfilling the objectives of the course (Dubinsky et. al 1994, 1998, 2001, Asiala et.al 1997, Burn 1996, Brown et.al 1997, Findell 2001, Fukawa Connelly 2007, Hirsch 2008, Kontorovich \& Zazkis, 2017).

My own experiences as an Abstract Algebra teacher of undergraduate and graduate students in Nepal motivated me for this study. Researches on how higher mathematics learning could be facilitated to the students have not been conducted in Nepalese context yet. Then, I analyze and unfold how mathematicians' ways of learning mathematics can be reconstructed from an andragogical perspective. My ultimate aim is to understand how learning of higher mathematics could be facilitated to the students in Nepalese context. 
Strategies of Learning Abstract Algebra

\section{OBJECTIVE AND RESEARCH QUESTION OF THE STUDY}

Learning of abstract algebra by undergraduate students was analyzed on the basis of cognitive learning theories. Dubinsky et.al (1994), Asila et.al (1996,1997), Edward \& Brenton (1996), Brown et.al (1997), Findell (2001), Mingus (2001), Fukuwa-connelly (2007), Hirsch (2008) have done experimental studies in explaining the learning of abstract algebra. Some of the aforementioned studies have utilized technology as tools for meaningful mediation of algebra contents and the learning for making meaningful understanding. The present study is however different than those, for it is based on traditional classroom setting with no computer assisted teaching in Nepalese context. The objective of the study was: to explain the learning strategies of undergraduate students in relation to learning of abstract algebra. In this context the following question arises as a research question.

What learning strategies do the undergraduate students employ in learningof abstract algebra?

\section{THEORETICAL FRAMEWORK}

The conceptual framework of the study was built on the Dubinsky"s APOS theory, and Vygotsky"s theoretical frameworks because to learn and teach abstract algebra, we have to pay a great deal of attention to the mental operations of the learners, use and meaning of various signs of the definitions, and purposeful interaction. In APOS theory, "genetic decomposition is a hypothetical model that describes the mental structures and mechanisms that the students might need to construct in order to learn a specific mathematical concept" (Arnon et al., 2014, p.27). According to APOS theory, individual makes sense of mathematical concepts by using certain mental structures i.e. Action, Process, Object, and schema (Piaget \& Garcia,1983/1989). These structures arise through instance of reflective abstraction or mental mechanism such as interiorization, coordination, reversal, encapsulation, and generalization- that lead to the construction of mental structures (Dubinsky, 1991).

A major theme of Vygotsky"s theoretical framework is that social interaction plays a fundamental role in the development of cognition. Vygotsky (1978, p.57) believed that "everything is learned on two levels". That is: first, on the social level, and later, on the individual level; first between people (interpsychological) and then inside the individual (intrapsychological). The potential for cognitive development is limited to a "Zone of proximal development" (ZPD). Vygotsky believed that internalization of semiotic mediation: the processes by which social processes are transformed into internal processes with the help of instruments of psychological activities, led to higher thinking skills.

To learn an abstract concept, spontaneous and scientific concepts should play an interdependent role. The concepts which are embedded in sense perception and practical/everyday experiences are called spontenious concepts. The concepts, which are acquired with conscious effort in the course of formal instructions, are called scientific concepts. "...the development of the spontaneous concepts proceeds upward and the development of scientific concept downwards..." (Vygotsky, 1986, p. 193). Vygotsky"s (1986, p.157) mentioned spontaneous and scientific concepts "are part of single process: the development of concept formation which is affected by varying external and internal conditions but is essentially a unitary process, not a conflict of antagonistic, mutually exclusive forms of thinking". Interaction between spontaneous and scientific concept within the Vygotsky"s Zone of Proximal Development (ZPD) fosters the development of supper-ordinate concepts (Vygotsky, 1986). Abstract algebraic concepts are not internalized directly, but through the use of psychological tools. The internalization of semiotics mediation induces to abstract algebraic concept formation, proof writing and problem solving in abstract algebra. Interaction within the ZPD changes the learner"s relationships to both his/her existing spontaneous and scientific concepts, facilitating a level of meta-cognition and self-reflection previously inaccessible. At the completion of two stages: interpsychological and intrapsychological in ZPD, students will be able to make schema of any abstract algebraic concepts and new understanding in abstract algebra. This development of concept formation will be proceeded not in a circle but in a spiral form, passing through the same point at each new evolution. Similarly, according to APOS theory, mental structures and mechanism by which mathematical ideas are constructed in the sequence of action-process-object-schema involves a spiral approach where new structures are built by acting on existing structures. In this approach, if once objects are constructed, then they can be transformed to make higher level action and then processes, and so on. This can continue indefinitely, but the lower level construction is not lost and it remains as a part of the enriched conception. 


\section{RESEARCH DESIGN}

The study used ethnographic design under qualitative approach in naturalistic setting to unpack the strategies for learning abstract algebra. As research tools for this study, the everyday journal writing by students (The journal of learning Group Theory), Non participant observation diary, clinical interviews with students, interviews guidelines for semi-structured interviews were used.

\section{SAMPLE}

All the students enrolled in the undergraduate with major mathematics in B.Ed/undergraduate program, from different colleges of Kathmandu Valley (private and constituent colleges were participants in the study for the purposes of field observations. All the participants had previously taken courses in Euclidean and non-Euclidean geometries, calculus, and real analysis. To select sample of the study, first I visited some private and constituent colleges. Having observations of some classes, interaction with students and teachers, studying students"written text and informal discussion on the basis of the written text from those colleges, I found, more or less students" learning styles, their difficulties regarding learning algebraic concepts, types of learners, teachers" delivered ways are similar. The key participants were selected by purposive sampling method. For that class observations, written tests (related to definition writing, to create examples and non-examples, proof writing), interviews were conducted. For interviewing students, issues were generated from preliminary analysis of the three sources of information: diaries, observation notes, and written tests. Later using all these information I came to know the limitations and potentials of the students which provided the tentative ZPD of each student. From this group of students I chose five students as key participants, who had given permission for full participation for the study, The key participants have been given pseudonyms.

\section{ANALYSIS AND INTERPRETATION}

As analysis techniques and interpretation, it was done from the very beginning of the field work focusing on the best solutions, common errors and the most frequently occurred errors, unanticipated and exceptional errors of students were sorted from the entire texts prepared from field study. The strategies of learning abstract algebra were analyzed and interpreted by using theoretical framework. Instantly some outstanding excerpts are:

\section{Example 1}

Ruma: How did you formulate the definition of a Normal Subgroup?

Bahadur [340]: $1^{\text {st }}$ I will remember some sentences (statements). Secondly, I make figure mentally from those statements. Thirdly, I remember important symbols. At last I write all these in language. For example: For definition of Normal Subgroup, (i) N is subgroup of group G (ii) therefore I think this figure mentally as follows.

(iii) $g n g^{-1} \in N$

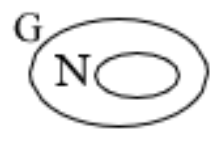

Here, students do not necessarily make the same distinctions as those made by mathematicians and mathematics educators.

Students cut up experiences in different ways, both indicating and further establishing a collection of concepts that are substantially and structurally different concepts that are used in mathematical community.

Example 2

Ruma: What do you mean by binary operation? Anu [51]: Binary Operation means + and $\times$

Bahadur [6]: Binary operation means,,$+- \times, \div$ but for group + and $\times$ 


\section{Example 2}

Ruma: Is $Z_{4}$ is subgroup of $Z_{8}$ ?

Nabin [22]: From this question it is clear that $Z_{8}$ is the group. Now I have to check is $Z_{4}$ is group or no. Let me to draw the group table for $\mathrm{Z}_{4}$ (he draws a piece of paper).

\begin{tabular}{|c|c|c|c|c|}
\hline$++_{4}$ & 0 & 1 & 2 & 3 \\
\hline 0 & 0 & 1 & 2 & 3 \\
\hline 1 & 1 & 2 & 3 & 0 \\
\hline 2 & 2 & 3 & 0 & 1 \\
\hline 3 & 3 & 0 & 1 & 2 \\
\hline
\end{tabular}

Here, all the elements of $Z_{4}$ are the elements of each row and column of the group table. All the elements of $Z_{4}$ occurred only one time in each row and column. So it is a group. One of the reasons behind this strategy is: enough examples of the concepts (e.g. Homomorphism, Isomorphim, Cyclic group) are not given in the text book. Only very few are given and the same examples are repeated in most of the textbook. On the other hand, teachers also discuss very few particular examples in the class.

\section{Example 3}

To prove particular theorems of prerequisites theorems of Lagrenges Theorems, students focused on particular relations. For instance

RME[308]: Could you explain how $a H=H$ iff $a$ belongs to $H$ ?

Bharat [305]: Let $h x$ be an arbitrary element of $a H$. Now by definition of $h H$ I mean definition of left coset, $x \in$ $h H$. Therefore $h x \in H$. Here, we know $h \in H, x \in H \Rightarrow h x \in H$. Thus, $h H \subset H \ldots \ldots . . .(i)$. Again, Let $a \in H$ then we can show $a \in h H$ and we can say $H \subset h H$. So, $x=(h h-1) x=h(h-1 x) \in h H$. Actually, I remember this step (laughs). But as the result of this step we will get $H \subset h H \ldots .$. (ii) From (i) and (ii) we can say $a H=H$. This completes the proof.

Bharat's line [305] reflects that to prove, he remembered some steps as formula. For example, here to show $H=$ $a H$, he focused on two relations: $h H \subset H$ and $H \subset h H$

Other-part, just he manipulated the symbols for these relations without having any clear reasoning. As someone looks the product (the proof), it seem that Bharat has understood the theorem. But in reality, due to this tactical technique only, in surface it looks like that he understood but indeed he did not know the real reasons about how these important steps appeared. This is very dangerous in the learning process of abstract algebra. Since, he recalled the important steps, he felt he knew all the things (he does not feel that he has to think again deeply), at the same time he did not know the reason behind each and every step. Here, for other steps of the theorem just he manipulated the symbols for the relations without any clear logic. Example- 4

Sometimes students focus on the "symbolic pattern" rather than reflecting thinking.

[251] Bharat: I think the inverse of 2 is $2^{-1}$ in $\mathrm{Z}_{6}=\{0,1,2,3,4,5\}$ because we know the inverse of $\mathrm{b}$ is $\mathrm{b}^{-1}$. Similarly the inverse of 3 is $3^{-1}$ so $3^{*} 3^{-1}=1$.

This wrong analysis is due to analogous to expecting ' 1 ' is the identity for operation and using the symbols looking its form rather than searching the meaning/sense for the symbols. So, in $Z_{6}$ he could not see the inverse of 2 is 4 and the inverse of 3 is 3 .

And he just searching $\frac{1}{2}$ and $\frac{1}{3}$ in $Z_{6}$ whilst $\frac{1}{2}, \frac{1}{3} \notin Z_{6}$. Another more

important fact is that his sentence "...because we know the inverse of $b$ is $b^{-1}$. Similarly, the inverse of 3 is $3^{-1}$, so $3 * 3^{-1}=1$ " reflected that for him, 1 (one) isthe identity element for all kind of structures. Here, the strategy of learning is seeking analogy from the previous schema. This is the most problematic situation to the teachers while teaching abstract algebra and a risk to the students to apply in solving problems, a mistaken ideas. Students usually try to make learning based on analogical reasoning using previous structure as learning strategy. But this strategy is not universally appropriate and the limitations of such strategies are informed to the students. 


\section{FINDINGS AND CONCLUSIONS}

This study made significant contributions to unpack the strategies of learning Abstract Algebra. On the completion of analyzing aforementioned examples this study found:

One of the learning strategies of undergraduate students to learn abstract algebra is to use the idiosyncratic figures like Bahadur's line [340], which is more or less similar to Findell's (2001) study where he found students do not necessarily make the same distinctions as those made by mathematicians and mathematics educators. Another students' strategy of Abstract algebra is to stuck on the particular concrete examples. For instance, Anu's line [51], Bahadur's line [6], and Nabin's line [22]. To use analogous reasoning: for instance, Bharat's line [251]. Students used different proof writing strategies for different contents. Strategy focused on figure: to prove two groups are Isomorphic student preferred the group table but when the order of group is large, changed the strategy: strategy focused on particular relation. For instance, Bharat's line [305]

These findings are not intended to stand as an indictment of the existing teaching and learning process of abstract algebra in undergraduate level, particularly in Nepal. Rather, the teaching learning of abstract algebra practices exhibited by students and teachers, outlined above, suggest that the concept of the combination of APOS theory and the ZPD of Vygotsky in teaching learning process of abstract algebra must take account of the existing practices and hidden barriers that facilitate and constrain both teachers and students in their teaching and learning process in course of scaffolding students' learning of abstract algebra. Consequently, the conclusions continue with the suggestion that all these findings are distinct and fundamental aspects of teaching and learning of advanced mathematics in general and particularly in abstract algebra.

\section{SOURCES OF FUNDING}

This research received no specific grant from any funding agency in the public, commercial, or not-for-profit sectors.

\section{CONFLICT OF INTEREST}

The author have declared that no competing interests exist.

\section{ACKNOWLEDGMENT}

None.

\section{REFERENCES}

[1] Arnon I., Cottrill J., Dubinsky E., Oktac A., Fuentes S.R., Triguerous M., \& Weller K.(2014). APOS Theory: A framework for Research and Curriculum Development in mathematics Education. New York: Springer.

[2] Asiala, M., Brown, A., DeVries, D. J., Dubinsky, E.,Mathews, D., \& Thomas, K. (1996). A framework for research and curriculum development in undergraduate mathematics education. In J. Kaput, A. H. Schoenfeld, \& E. Dubinsky (Eds.), Research in Collegiate mathematics education, II (pp. 1-32). Providence, RI: American Mathematical Society.

[3] Asiala, M., Dubinsky, E., Mathews, D.M., Morics, S., \& Oktac, A. (1997). Development of students" understanding of cosets, normality, and quotient groups. Journal of Mathematical Behavior, 16, 241-309

[4] Brown, A., DeVries, D.J., Dubinsky, E., \& Thomas, K. (1997). Learning binary operations, groups and subgroups. Journal of Mathematical Behavior, 16, 187-239.

[5] Burn, B.(1996).What are the fundamental concept of group theory? Educational Studies in Mathematics, 31, 371-378

[6] Devlin, K. (2000). The math gene. New York: Basic Books.Dubinsky, E. (1991). Reflective abstraction in advanced mathematical thinking . In D. Tall (Ed.), Advanced Mathematical Thinking, Kluwer Academic Press, pp.95-123 
[7] Dubinsky, E., Dautermann, J., Leron, U., \& Zazkis, R. (1994). On learning fundamental concepts of group theory. Educational Studies in Mathematics, 27(3), 267-305.

[8] Dubinsky, E., Elterman, F. \& Gonc, C. (1998). The student"s construction of quantification. For the Learning of Mathematics 8(2), 44-51

[9] Dubinsky, E. \& McDonald M. (2001). APOS: A constructivist theory of learning in undergraduate mathematics education research. In Derek Holton et al. (Eds) The teaching and learning of mathematics at university level: An ICME study (pp. 273-280) Netherlands: KluwerFindell, B. (2001). Learning and understanding in abstract algebra. Unpublished Doctoral Dissertation, The University of New Hampshire Association of America.

[10] Fukawa-Connelly, T. (2007). A tale of two courses: Teaching and learning undergraduate abstract algebra. Unpublished Doctoral Dissertation, The University of Maryland College ParkHirsch, J. (2008).Tracking changes in teaching and learning abstract algebra; Beliefs and ability to abstract. Unpublished Doctoral Dissertation, Columbia University USA

[11] Kontorovich, I., \& Zazkis, R. (2017). Mathematical conventions: Revisiting arbitrary and necessary. For the Learning of Mathematics, 37(1), 29-34.Maasz J. \& Schloeglmann W. (2006). New Mathematics Education Research and Practice. The Netherlands: Sense Publishers.

[12] Mingus, T. (2001). A case study of spiraling content and pedagogy through core courses for pre-service secondary mathematics teachers. In M. Ahmadi (Ed.), Reading in innovative ideas in teaching collegiate mathematics (pp. 191-213). Lanham, MD: University Press of America.

[13] Piaget, J., \& Gracia, R. (1989). Psychogenesis and the history of science. (H. Feider, Trans.) New York: Colombia University Press. (Original work published 1983).

[14] Vygotsky, L. S. (1978). Mind in society: The development of higher psychological processes.Cambridge, MA: Harvard University Press.

[15] Vygotsky, L.S. (1986). Thought and language. Cambridge, MA: MIT Press. 